\title{
Usage of medicinal plants and its determinant factors in Kerman, Iran
}

\begin{abstract}
Background: in recent years, medicinal plants have been increasingly paid attention to and many studies have been done on this regard. Therefore, a health care provider especially nurses should know the increasing models of such treatment for a holistic care. The aim of present study was to investigate prevalence of using medicinal plants, causes of using it and users' satisfaction among outpatients in Kerman, Iran.
\end{abstract}

Method: this was a descriptive-analytic study. 288 subjects participated in the study using convenience sampling method. To collect the information, a demographic form and a researcher-made questionnaire for studying the usage of medicinal plants, clinical complaints leading to using this treatment and satisfaction of the user, was used. The questionnaire had sufficient validity and reliability.

Results: prevalence of using medicinal plants was $77.4 \%$ in previous year. The most common clinical symptoms leading to using this treatment were common cold $(31.8 \%)$ and migraine $(9.9 \%)$. The highest frequency related to the satisfaction items belonged to the item "safety of medicinal plants" (93.3\%)

Conclusion: this study showed that the usage of medicinal plants is very common among outpatients and the belief about the safety of medicinal plants has been the most important therapeutic outcome resulting in more satisfaction of users.

Keywords: prevalence, medicinal plant, herbal medicine, symptoms, satisfaction
Volume 3 Issue 2 - 2017

\begin{abstract}
Akbar Sheikhrabori,' Mahlagha Dehghan, ${ }^{2}$ Masoumeh Salari, ${ }^{3}$ Fateme Ghaedi ${ }^{4}$

'Deparment of Nursing, Iran University of Medical Sciences, Iran ${ }^{2}$ Nursing Research Center, Kerman University of Medical

Sciences, Iran

${ }^{3}$ Deparment of Nursing, Kerman University of Medical Sciences, Iran

${ }^{4}$ Deparment of Nursing, Isfehan University of Medical Sciences, Iran
\end{abstract}

Correspondence: Fateme Ghaedi, School of Nursing and Midwifery, Isfehan University of Medical Sciences, Iran, Tel +983। 37922968 , Fax +9831 36247080 , Email Fatemeh.ghaedi@gmail.com

Received: November 15, 2016 | Published: July 03, 2017
Abbreviations: WHO, world health organization; CAM, complementary alternative medicine; NCCAM, national center for complementary \& alternative medicine

\section{Introduction}

According to world health organization (WHO), complementary \& alternative medicine (CAM) is a wide range of health care acts which are not included in health care systems of all countries. Therefore, CAMs are various and according to classification of national center for complementary \& alternative medicine (NCCAM) in America, CAMs are biology therapy, body-mind therapy, physical therapy with manipulation, energy therapy and care systems. ${ }^{1}$ Concerning evidences, one of the most prevalent kinds of CAMs is biological therapies..$^{2,3}$ These treatments use natural materials including essential oils, medicinal plants, nutrient supplementary and special diets, and other products such as cartilage. ${ }^{4,5}$ Concerning easy access to medicinal plants, they are used increasingly by people throughout the world. ${ }^{6}$ However, most of care givers have underestimated the amount of using these treatments by patients because most of patients do not speak about this issue with their care providers ${ }^{7}$ while some of products of CAM such as medicinal plants interfere with medications of the common medicine. ${ }^{2}$ For example, garlic and ginger can cause severe bleeding and ginseng creates hypertension and arrhythmia. ${ }^{2}$ Therefore, health care providers should ask their patients about consumption of such products. ${ }^{8}$

Nurses play important role in presenting primary health services to patients and they are accounted as pioneers of health services. ${ }^{9}$ Therefore, it is necessary that they know the increasing models of CAM application for a holistic care ${ }^{10}$ and this requires information about important dimensions such as satisfaction from given cares and demographic variables of users, because application of all CAMs is affected by cultural and demographic factors. ${ }^{11}$ Since the prevalence of using medicinal plants, complaints resulted in using this CAM and satisfaction of using medicinal plants has not been studied individually, we decided to study usage of medicinal plants and its determinant factors in outpatients referred to Besat Clinic located at Kerman. The results of this study might conduct more studies on effectiveness of medicinal plants in Iranian culture and might be useful in caring-therapeutic planning.

\section{Material and methods}

\section{Study design and setting}

This was a cross-sectional study conducted in Beast clinic of Kerman, Iran. This is the only educational center for outpatient specialized and sub-specialized cares in Kerman city.

\section{Sampling and sample size}

Convenience sampling was used to select the subjects. In order to estimate sample size, the following formula was used:

$$
n=\frac{\mathrm{z}^{2} \times \mathrm{p}(1-\mathrm{p})}{\mathrm{d}^{2}}
$$

The amount of $p$ and $1-p$ were considered 0.5 in order to estimate maximum sample size. The amount of $d$ was considered 0.06 . Based on this formula, the estimated sample size was 268 . In addition, to consider the probability of drop out 20 extra subjects were added to estimated sample size.

\section{Instrument}

To gather information, a two-part questionnaire was used. The first part was included socio-demographic data such as age, gender, 
married status, education, job, income and having chronic disease. The second part was a researcher-made questionnaire for studying the frequency of using medicinal plants, problems and diseases that persuade the user to use such method and his/her satisfaction from this method. The amount of usage has been measured by yes or no answers and if the answer is yes, it has been estimated based on patient's report on number of using the technique in last year. Patient's complaints or problems include; 1-backache, 2-pain in knee, 3-migraine, 4-other chronic pains, 5-kidney stone, 6-depression, 7-anxiety, 8-mental disorders, 9-mental retarded, 10-skin disease, 11-allergy, 12-obesity, 13-thinness, 14-anorexia, 15-cold, 16-malnutrition, 17-irritable bowel syndrome, 18-hypothyroidism, 19-hyperthyroidism, 20-diabetics, 21-hypertension, 22-chronic fatigue, 23-asthma, 24-sleep disorders, and 25 -others. In addition, amount of satisfaction was measured by using an eight item scale about accessibility, easy usage, harmlessness, no interference with routine activities, relief of symptoms, no concern for interfering with other therapeutic methods, feeling well after using treatment and suggesting the method to others. This scale was scored by Likert's five point scale ( $4=$ very satisfied, $3=$ satisfied, $2=$ unsatisfied, $1=$ very unsatisfied and $0=$ no idea). Based on mean scores of the satisfaction scale, the scores range from zero to four and higher score shows higher satisfaction from using medicinal plants. The mean scores $\geq 2.5$ considered as satisfied and the mean scores below 2.5 considered as unsatisfied. In order to obtain content and face validity, books, sources and opinions of ten faculty members of Isfahan University of Medical Science who has trained in CAM was used and the questionnaire has been assessed regarding clarity, easy usage and the time required for its completion. Also a pilot study was done on 30 persons of the target population and its reliability was measured by using Cronbach's alpha (0.82).

\section{Data collection and analysis}

In present study, the target population was all clients referring to Best clinic of Kerman. People older than 15 years with mental and physical ability to answer the questions were eligible to participate in the study. The questionnaires were given to subjects in order to be completed in form of self-report. In case the subject was illiterate, the questionnaire was completed by the researcher. Sampling was taken from beginning of June to late June 2015. Data were analyzed by SPSS version 18. Descriptive statistic (frequency, percentage, mean and standard deviation) was applied to describe amount of usage and satisfaction from medicinal plants and logistic regression was used to determine the relation between demographic characteristics and being user of medicinal plants. Significance level was considered by 0.05 .

\section{Ethical consideration}

Kerman University of Medical Science (KUMS) approved this project. After approval, the permission offered to the management of Basat clinic. The researcher offered some oral information to the participants including the goals and objectives of the study, the confidentiality and anonymity of the data, and that they were free to withdraw from the study at any time. Verbal consent was given individually.

\section{Results}

\section{Socio-demographic characteristics}

In total, 288 participants were assessed. The mean age of participants was $38.72 \pm 13.38$ years. Less than $45 \%$ of them were men. Nearly $80 \%$ were married. Less than $10 \%$ were illiterate and unemployed. More than half of participants had less than 1000000 to man (nearly 450 US dollar) income monthly. Less than $10 \%$ of participants lived in the village. $86.5 \%$ of participants had at least one chronic disease and the most prevalent diseases were migraine (18.1\%), hypertension (17.7\%) and anemia (17\%) respectively. Note 15 clients rejected to participate in the study, so the drop out value was $5.21 \%$. In addition there were no missing data.

\section{Findings}

Totally $77.4 \%(n=223)$ of the participants had used at least one kind of medicinal plants in the previous year. The frequency of using medicinal plants varied between 3 to 500 times (median=100, mode $=100$ ). The most prevalent causes of using medicinal plants were common cold $(31.8 \%)$, migraine $(9.9 \%)$, hypertension $(8.5 \%)$, diabetes $(6.7 \%)$, backache (5.8\%), depression (5.4\%), knee pain $(4.9 \%)$, allergy (4.9\%), sleep disorders $(4.9 \%)$, and chronic fatigue $(4.5 \%)$ respectively. Other causes of using medicinal plants were anxiety, anorexia, asthma, hypothyroidism, and other chronic pains Table 1.

Table I Description of the study sample $(n=288)$

\begin{tabular}{|c|c|c|}
\hline Variables & Frequency* & Valid percent \\
\hline \multicolumn{3}{|l|}{ Age $(y r)$} \\
\hline $15-25$ & 42 & 14.6 \\
\hline $26-35$ & 90 & 31.3 \\
\hline $36-45$ & 81 & 28.1 \\
\hline $46-55$ & 41 & 14.2 \\
\hline$>55$ & 34 & 11.8 \\
\hline \multicolumn{3}{|l|}{ Sex } \\
\hline Male & 126 & 43.8 \\
\hline Female & 162 & 56.3 \\
\hline \multicolumn{3}{|l|}{ Marital Status } \\
\hline Single & 48 & 16.7 \\
\hline Married & 227 & 78.8 \\
\hline other** & 13 & 4.5 \\
\hline \multicolumn{3}{|l|}{ Education } \\
\hline Illiterate & 27 & 9.4 \\
\hline Under Diploma & 68 & 23.6 \\
\hline Diploma & 77 & 26.7 \\
\hline Academic degree & 116 & 40.3 \\
\hline \multicolumn{3}{|l|}{ Job } \\
\hline Housewife & 124 & 43.1 \\
\hline Unemployed & 24 & 8.3 \\
\hline Employed & 129 & 44.8 \\
\hline Pensioner & 11 & 3.8 \\
\hline \multicolumn{3}{|c|}{ Family Income Per Month } \\
\hline$<500000$ & 62 & 21.5 \\
\hline $500000-1000000$ & 101 & 35.1 \\
\hline $100000 \mid-1500000$ & 88 & 30.6 \\
\hline$>1500000$ & 37 & 12.8 \\
\hline
\end{tabular}


Table Continued...

\begin{tabular}{lll}
\hline Variables & Frequency* & Valid percent \\
\hline Living Place & 269 & 93.4 \\
City & 19 & 6.6 \\
Village & & \\
Disease & 39 & 13.5 \\
No chronic disease & 34 & 11.8 \\
Rheumatoid arthritis/ Osteoarthritis & 42 & 14.6 \\
Hernia disc & 49 & 17 \\
Anemia & 52 & 18.1 \\
Migraine & 51 & 17.7 \\
Hypertension & 41 & 14.2 \\
Diabetes & 36 & 12.5 \\
Neuropsychological disease & 33 & 11.4 \\
Asthma/ Allergy & 15 & 5.2 \\
Chronic skin disease & 15 & 5.2 \\
Thyroid disease & 23 & 8 \\
Heart disease & 32 \\
\hline
\end{tabular}

*The variables that had less than total 500 frequencies are because of missing values.

**Widowed or divorced.

Iran currency (nearly each US dollar is equal to 3200 to man).

The mean score of satisfying of using medicinal plants was $2.98 \pm 0.67$. According to the cut point of $2.5,85.2 \%(n=190)$ of participants were satisfied of using medicinal plants. According to different aspects of satisfaction, $89.7 \%$ of participants were satisfied about continued access to procedures, $92.4 \%$ were satisfied about ease of use, $93.3 \%$ were satisfied about safety of medicinal plants, $81.6 \%$ believed that using medicinal plants did not interfere with their daily activities, $89.7 \%$ were satisfied of relief of symptoms, $86.1 \%$ did not have any concern about having interactions between medicinal plants and other therapies, $92.3 \%$ had good feeling after use of medicinal plants and $86.1 \%$ recommended medicinal plants to others.

To check the association between being user of medicinal plants and Socio-demographic characteristics, univariate logistic regression was performed. We further adjusted the model using multivariate logistic regression Table 2. Based on the results, Adjusted odd ratio showed that using medicinal plants in participants with academic education was 4 times more than illiterate participants $(C=1.16-13.8$, $\mathrm{P}$ value $=0.03$ ). Note we did not found any association between being user of medicinal plants and other socio-demographic characteristics.

\section{Discussion}

Findings showed that $78 \%$ of persons who participated in the study used medicinal plants during last year. In the study done on 502 clients who referred to Diabetes clinics in Tehran and Islamshahr in 2014 , indicated that in addition to their medications, $70.3 \%$ of diabetic patients used medicinal plants and those plants that were known for control of blood sugar. ${ }^{12}$ In this direction, ${ }^{13}$ conducted a descriptivesectional study on 1449 women referred to therapeutic-health centers in Shahr-e Kord and concluded that $68.3 \%$ of subjects used medicinal plants during last year. ${ }^{13}$ Also, in the study done by Hapner, $68.2 \%$ of participants used medicinal plants. ${ }^{14}$ The study done by Planta suggested that $56 \%$ of persons used medicinal plants to remove their spiritual and physical problems. ${ }^{15}$ Another study done by Jose et al. ${ }^{16}$ indicated that $9.8 \%$ of participants used medicinal plants within two weeks ago. Deanne et al. ${ }^{17}$ found that of 137 patients with AIDS, $63.5 \%$ of them used medicinal plants after disease diagnosis. Results of above studies were in agreement with those of this study. Using complementary medicine and traditional treatments are common in different races throughout the world and many modern treatments in modern medicine originated from these complementary treatments.

Table 2 Uni-factor logistic regression Model for being user of medicinal plants, With Adjustment for All Listed Variables

\begin{tabular}{|c|c|c|c|c|c|c|}
\hline \multirow[t]{2}{*}{ Variables } & \multicolumn{3}{|c|}{ Uni-factor logistic regression } & \multicolumn{3}{|c|}{ Multifactor logistic regression } \\
\hline & $\mathbf{O R}^{*}$ & $\mathrm{Cl} * *$ & $P$ value & OR & $\mathrm{Cl}$ & $P$ value \\
\hline \multicolumn{7}{|l|}{ Age (yr) } \\
\hline $15-25$ & 1 & & 0.99 & I & & 0.57 \\
\hline $26-35$ & 1.03 & $0.43-2.43$ & 0.95 & 0.67 & $0.24-1.88$ & 0.45 \\
\hline $36-45$ & 1.18 & $0.48-2.86$ & 0.72 & 1.11 & $0.35-3.49$ & 0.86 \\
\hline $46-55$ & I.II & $0.40-3.10$ & 0.84 & 1.26 & $0.34-4.59$ & 0.73 \\
\hline$>55$ & 1.2 & $0.40-3.60$ & 0.73 & 1.68 & $0.40-6.99$ & 0.48 \\
\hline \multicolumn{7}{|l|}{ Sex } \\
\hline Male & 1 & & & I & & \\
\hline Female & 1 & $0.57-1.75$ & $>0.99$ & 0.86 & $0.34-2.18$ & 0.75 \\
\hline \multicolumn{7}{|c|}{ Marital status } \\
\hline Single & I & & 0.74 & I & & 0.75 \\
\hline Married & 1 & $0.48-2.10$ & 0.99 & 0.79 & $0.28-2.25$ & 0.66 \\
\hline other** & 3.27 & $0.38-28.21$ & 0.28 & $2.4 I$ & $0.22-26.6$ & 0.47 \\
\hline
\end{tabular}


Table Continued....

\begin{tabular}{|c|c|c|c|c|c|c|}
\hline \multirow[t]{2}{*}{ Variables } & \multicolumn{3}{|c|}{ Uni-factor logistic regression } & \multicolumn{3}{|c|}{ Multifactor logistic regression } \\
\hline & $\mathbf{O R}^{*}$ & $\mathrm{Cl}^{* * *}$ & $P$ value & OR & $\mathbf{C l}$ & $P$ value \\
\hline \multicolumn{7}{|l|}{ Education } \\
\hline illiterate & I & & 0.08 & I & & 0.03 \\
\hline Under Diploma & 1.01 & $0.38-2.68$ & 0.98 & 1.12 & $0.39-3.18$ & 0.84 \\
\hline Diploma & 1.28 & $0.48-3.41$ & 0.61 & 1.67 & $0.52-5.32$ & 0.39 \\
\hline Academic degree & 2.45 & $0.93-6.49$ & 0.07 & 4 & $1.16-13.8$ & 0.028 \\
\hline \multicolumn{7}{|l|}{ Job } \\
\hline Housewife & I & & 0.83 & 1 & & 0.78 \\
\hline Unemployed & 0.71 & $0.27-1.88$ & 0.49 & 0.48 & $0.12-1.94$ & 0.3 \\
\hline Employed & I.I & $0.61-2.0$ & 0.75 & 0.73 & $0.25-2.08$ & 0.55 \\
\hline Pensioner & 1.31 & $0.27-6.43$ & 0.74 & 0.81 & $0.12-5.58$ & 0.83 \\
\hline \multicolumn{7}{|l|}{ Family Income Per Month } \\
\hline$<500000$ & I & & 0.47 & I & & 0.92 \\
\hline $500000-1000000$ & 1.56 & $0.75-3.23$ & 0.23 & 1.28 & $0.58-2.78$ & 0.54 \\
\hline $100000 I-1500000$ & 1.49 & $0.70-3.14$ & 0.3 & 1.04 & $0.43-2.54$ & 0.93 \\
\hline$>1500000$ & 2.11 & $0.75-5.93$ & 0.16 & 1.21 & $0.36-4.09$ & 0.76 \\
\hline \multicolumn{7}{|l|}{ Living Place } \\
\hline City & 1 & & & I & & \\
\hline Village & 0.6 & $0.22-1.64$ & 0.32 & 0.8 & $0.27-2.38$ & 0.68 \\
\hline \multicolumn{7}{|l|}{ Disease } \\
\hline No chronic disease & I & & & I & & \\
\hline At least one chronic disease & 1.45 & $0.68-3.11$ & 0.34 & 1.26 & $0.56-2.84$ & 0.57 \\
\hline
\end{tabular}

\section{*Odds ratio.}

***Confidence interval.

Iran currency nearly each US dollar is equal to 3450 to man.

The most common complaints resulted from using medicinal plants in present study were common cold (32\%) and migraine (10\%) that were in agreement with results of Sereshti et al.. ${ }^{13}$ They indicated that the most common cause of using medicinal plants was catching a cold (29.47). ${ }^{13}$ In a systematic review on the most important medicinal plants and their place in treating diseases, Khonsari et al. ${ }^{18}$ studied 7862 papers and found that application of medicinal plants was common in five classes of diseases as follows: neuro-psychological diseases, immune and inflammatory diseases, digestive diseases, cardiovascular diseases, and cancer. Results of this study were not in agreement with those of the present study. The reason may be due to different types of using medicinal plants in climatic condition, place of planting, access to medicinal plants, experience of people in using plants for different diseases and amount of their effects, different believes in medicines and plants.

Totally in the present study, the majority of the participants were satisfied of using medicinal plants from different aspects of continued access to procedures, ease of use, safety of medicinal plants, not interfering with daily activities, relief of symptoms, not having interactions between medicinal plants and other therapies, and good feeling after use of medicinal plants. Stated that the most common reasons for using medicinal plants are their accessibility $(32.6 \%)$ and effectiveness (14.6\%). These results are in agreement with those of this study. It can be said that based on geographical condition and vegetations of different regions and the weather condition, amount of access to medicinal plants is different and it affects application of medicinal plants. However, studying, recognizing and having more information about medicinal plants can play critical role in application of correct and scientific methods of them. ${ }^{12}$ Based on the present findings and using multivariate logistic regression, amount of using medicinal plants among educated people was 4 times higher than illiterate ones but there was no relationship between other demographic variables and usage of medicinal plants. In this direction, the study done by Awad et al. ${ }^{19}$ on diabetic patients in Kuwait indicated that using medicinal plants has significant relationship with education of patients and amount of using medicinal plants in people with low education was higher. Oldendick conducted a study on 1584 persons older than 18 years and results suggested that those with university education used medicinal plants more than others. ${ }^{20}$ In addition, Ghaedi et al. ${ }^{21}$ in their study showed that the usage of CAM was 3.22 times higher in people with academic education when compared with 
illiterate people. Therefore the literatures are controversial about the relation between education and using medicinal plants. However as we used multivariate logistic regression, this may reduce confounders effect and result in more concise finding.

\section{Conclusion}

Medicinal plants are a method for removing symptoms of diseases. In this method, effective material of plants can remove disease symptoms and recover health of the patient. In fact, this method is a type of drug therapy and instead of using chemical medications, medicinal plants are used. Today and especially in recent years, general tendency to using medicinal plants and natural products is increasing in the world. Based on previous studies, it is clear that medicinal plants like chemical medications have side effects in addition to positive effects. Therefore, it is important to know sufficiently medicinal plants and how to use them for control of diseases. Therefore, it is necessary that information of people about medicinal plants and how to use them be increased. Physicians and nurses should increase their information in this regard and medicinal plants should be educated correctly along with patient treatment regimen. Further study suggested evaluating effects and safety of medicinal plants.

\section{Acknowledgements}

Special thanks to all clients who took part in this study. The authors appreciate the personnel at the Best clinic for their contribution in data collection.

\section{Conflict of interest}

There is no conflict of interest to be declared.

\section{References}

1. Stewart D, Pallivalappila AR, Shetty A, et al. Healthcare professional views and experiences of complementary and alternative therapies in obstetric practice in North East Scotland: a prospective questionnaire survey. BJOG. 2014;121(8):1015-1019.

2. Kramlich D. Introduction to complementary, alternative, and traditional therapies. Crit care nurse. 2014;34(6):50-56

3. Hok J, Tishelman C, Ploner A, et al. Mapping patterns of complementary and alternative medicine use in cancer: An explorative cross sectional study of individuals with reported positive "exceptional" experiences. BMC Complemen Altern Med. 2008;8:48.

4. Barnes PM, Bloom B, Nahin RL. Complementary and alternative medicine use among adults and children: United States, 2007. Natl Health Stat Rep. 2008;10(12):1-23.

5. Ruth Lindquist, Mariah Snyder, Mary Fran Tracy. Complementary and Alternative Therapies in Nursing. USA: Springer Publishing Company; 2009.
6. Kennedy J. Herb and supplement use in the US adult population. Clin Ther. 2005;27(11):1847-1858.

7. Geisler C, Cheung C, Johnson Steinhagen S, et al. Nurse practitioner knowledge, use, and referral of complementary/alternative therapies. $J$ Am Assoc Nurse Pract. 2015;27(7):380-388.

8. Caspi O, Koithan M, Criddle MW. Alternative medicine or "alternative" patients: A qualitative study of patient-oriented decision-making processes with respect to complementary and alternative medicine. Med Decis Making. 2004;24(1):64-79.

9. American Association of Nurse Practitioners; 2010.

10. Zanini A, Quattrin R, Goi D, et al. Italian oncology nurses' knowledge of complementary and alternative therapies: national survey. $J$ Adv Nurs. 2008;62(4):451-456

11. Harris PE, Cooper KL, Relton C, et al. Prevalence of complementary and alternative medicine (CAM) use by the general population: a systematic review and update. Int J Clin Pract. 2012;66(10):924-939.

12. Shahandokht N, Nojomi M, Moradilakeh $\mathrm{M}$, et al. The common herb in self herbal medication in diabetic patients refer to diabetes medical health center. IJDLD. 2014;13(5):413-424.

13. Sereshti M, Azari P. Prevalence use of herbal drug and attitude of women about use of herbal product among women refer to health care center in Shahrekord. Journal of Knowledge \& Health. 2008;2(4):21-28.

14. Hepner DL, Harnett M, Segal S, et al. Herbal medicine use in parturients. Anesth Analg. 2002;94(3):690-693.

15. Planta M, Gundersen B, Petitt JC. Prevalence of the use of herbal products in a low-income population. Fam Med. 2000;34(4):252-257.

16. Loera JA, Black SA, Markides KS, et al. The use of herbal medicine by older mexican Americans. J Gerontol A Biol Sci Med Sci. 2001;56(11):M714-718.

17. Langlois-Klassen D, Kipp W, Jhangri GS, et al. Use of traditional herbal medicine by AIDS patients in kabarole district, Western Uganda. Am J Trop Med Hyg. 2007;77(4):757-763.

18. Khonsari A, Gorji K, Mousavi A, et al. Systematic review of the most important medicinal plants and place them in the international treatment of diseases. Yafteh. 2010;11(5):45-56.

19. Awad A, Al-Raiy S, Abahussain E. Self-Medication practices among diabetic patients in kuwait. Med Princ Pract. 2008;17(4):315-320.

20. Oldendick R, Coker AL, Wieland D, et al. Population-based survey of complementary and alternative medicine usage, patient satisfaction, and physician involvement. South carolina complementary medicine program baseline reseach team. South Med J. 2000;93(4):375-381.

21. Ghaedi F, Dehghan M, Salari M, et al. Complementary and alternative medicines: Usage and Its determinant factors among outpatients in southeast of Iran. J Evid Based Complementary Altern Med. 2015. 